\title{
MxB impedes the NUP358-mediated HIV-1 pre-integration complex nuclear import and viral replication cooperatively with CPSF6
}

\author{
Linlin Xie ${ }^{1 \dagger}$, Lang Chen ${ }^{1 \dagger}$, Chaojie Zhong ${ }^{1}$, Ting Yu ${ }^{1}$, Zhao Ju' ${ }^{1}$, Meirong Wang ${ }^{1}$, Hairong Xiong ${ }^{1}$, Yan Zeng ${ }^{2}$,
} Jianhua Wang ${ }^{3}$, Haitao $\mathrm{Hu}^{4}$, Wei Hou ${ }^{1 *}$ and Yong Feng ${ }^{1 *}$ (1)

\begin{abstract}
Background: The human myxovirus resistance $2(\mathrm{M} \times 2 / \mathrm{M} \times \mathrm{B})$ protein was originally found to regulate cytoplasmicnuclear transport but was recently reported to restrict HIV-1 replication by binding to HIV-1 capsid (CA), preventing uncoating, the nuclear import of pre-integration complex (PIC) and viral DNA integration. This work explores the mechanisms of MxB-mediated HIV-1 inhibition.
\end{abstract}

Results: We demonstrated that MxB represses NUP358-mediated PIC nuclear import and HIV-1 replication. Moreover, MxB's effects on PIC nuclear import and HIV-1 replication depend critically on cofactor cleavage and polyadenylation specificity factor subunit 6 (CPSF6). MxB binds nucleoporin NUP358, blocks NUP358-CA interaction, thereby impeding the nuclear import of HIV-1 PIC with CPSF6 binding to PIC. More intriguingly, CPSF6's role in nuclear import depends on $\mathrm{MxB}$, being a facilitator of $\mathrm{HIV}-1$ nuclear import on its own, but becoming an inhibitor when $\mathrm{M} \times \mathrm{B}$ is present.

Conclusions: Our work establishes that MxB impedes the NUP358-mediated HIV-1 nuclear import and viral replication cooperatively with CPSF6.

Keywords: HIV-1, Nuclear import, Nucleoporin, MxB, CPSF6

\section{Background}

Human Myxovirus resistance protein $2(\mathrm{Mx} 2 / \mathrm{MxB})$, a member of the dynamin-like large GTPases that belong to the dynamin superfamily, was originally found to regulate cell-cycle progression and cytoplasmic-nuclear transport [1], but recently was demonstrated to inhibit the infection of various viruses, including HIV-1 [2-4], Herpesviruses [5, 6], HTNV [7], HCV [8], HBV [9] and other lentiviruses such as SIV, EIAV and FIV [2]. Human $\mathrm{MxB}$ was reported to target the HIV-1 capsid protein

\footnotetext{
*Correspondence: houwei@whu.edu.cn; yongfeng@whu.edu.cn ${ }^{\dagger}$ Linlin Xie and Lang Chen contributed equally to this work

${ }^{1}$ State Key Laboratory of Virology/Institute of Medical Virology/Hubei Province Key Laboratory of Allergy \& Immunology, School of Basic Medical Sciences, Wuhan University, Wuhan, Hubei, People's Republic of China

Full list of author information is available at the end of the article
}

(CA) after cell entry [10-13], to prevent uncoating [14], nuclear import of the viral pre-integration complex (PIC, composed of viral components include viral DNA, integrase (IN), nucleocapsid (NC), matrix (MA), viral protein $\mathrm{R}(\mathrm{Vpr})$, and reverse transcriptase (RT); several host proteins including lens epithelium-derived growth factor (LEDGF/p75), barrier-to-autointegration factor (BAF), and integrase interactor 1 (INI1) $[15,16]$ ) and subsequent chromosomal integration of the proviral DNA into the host genome, but did not affect reverse transcription [2$4,17,18]$. However, the accurate time and spatial details of MxB-mediated HIV-1 inhibition remain unclear.

HIV-1 replication requires active transport of viral PIC from the cytoplasm to the nucleus through a $30 \sim 50 \mathrm{~nm}$ in diameter channel formed by the nuclear pore complex (NPC), which is too small for PIC passive diffusion [19-21]. Each NPC is composed of $\sim 30$ different protein

c) The Author(s) 2020. This article is licensed under a Creative Commons Attribution 4.0 International License, which permits use, sharing, adaptation, distribution and reproduction in any medium or format, as long as you give appropriate credit to the original author(s) and the source, provide a link to the Creative Commons licence, and indicate if changes were made. The images or other third party material in this article are included in the article's Creative Commons licence, unless indicated otherwise in a credit line to the material. If material is not included in the article's Creative Commons licence and your intended use is not permitted by statutory regulation or exceeds the permitted use, you will need to obtain permission directly from the copyright holder. To view a copy of this licence, visit http://creativeco mmons.org/licenses/by/4.0/. The Creative Commons Public Domain Dedication waiver (http://creativecommons.org/publicdomain/ zero/1.0/) applies to the data made available in this article, unless otherwise stated in a credit line to the data. 
constituents called nucleoporins (NUPs). In the context of the nuclear pore, the nucleoporin protein NUP358 forms a basket on the cytoplasmic side of the NPC [22]. NUP358 binds the Cyclophilin A (CypA) binding loop of HIV-1 CA via its C-terminal cyclophilin domain (NUP358Cyp) and has been reported to facilitate HIV-1 infection and core disassembly (uncoating) [23, 24]. Several studies further demonstrated that HIV-1 preferentially relies on NUP358 to enter the nuclei of host cells [23, 25-27].

The cleavage and polyadenylation specificity factor subunit 6 (CPSF6) also binds HIV-1 CA and facilitates the interaction between HIV-1 cores and NUP358 [28], indicating a positive role for CPSF6 in HIV-1 nuclear import $[27,29,30]$. CPSF6 ${ }_{1-358}$, a truncated version of CPSF6, impedes nuclear import of HIV-1 PIC, indicating that full length of CPSF6 is required for its role in helping PIC nuclear import [31, 32]. Notably, relative to the wild-type HIV-1 $\left(\mathrm{HIV}-1_{\mathrm{WT}}\right), \mathrm{HIV}-1_{\mathrm{N} 74 \mathrm{D}}$, which bears the capsid mutation N74D, abolishes CA binding to CPSF6 $[27,33]$, differs in host nuclear transport and dependence on nuclear pore proteins including NUP358, NUP98 and Transportin 3 (TNPO3), all of which have been shown to be important for HIV-1 ${ }_{W T}$ infection [20, 27, 34-37]. These observations highlight the diverse functions played by CPSF6, together with NUP358 during the nuclear import step of the HIV-1 replication cycle.

$\mathrm{MxB}$ exists in two isoforms, a long $78 \mathrm{kDa}$ and a short $76 \mathrm{kDa}$ molecule. The long $78 \mathrm{kDa}$ isoform contains a nuclear localization signal (NLS) on its N-terminal 25 amino acids that localizes the protein preferentially to the nuclear pores, while the short $76 \mathrm{kDa} \mathrm{MxB}$ isoform is lacking the NLS and is cytoplasmic. Notably, only the long $78 \mathrm{kDa}$ isoform displays anti-HIV-1 activity [18]. Indeed, mutational analysis has demonstrated the $\mathrm{N}$-terminal domain, which contains a triple arginine (RRR) motif at positions 11 to 13 , is important for mediating antiviral activity of the MxB against HIV-1 [11, 13, 38, 39]. Additionally, HIV-1 CA is the viral determinant for MxB to inhibit HIV-1 infection [10, 17, 40]. One of the most important pieces of evidence supporting this notion is that $\mathrm{HIV}-1_{\mathrm{N} 74 \mathrm{D}}$ is insensitive to $\mathrm{MxB}$ restriction [3]. Interestingly, the capsid mutation N74D abolishes CA binding to CPSF6 protein, but does not reduce $\mathrm{MxB}$ binding to the CA assemblies [10]. All of these facts indicate that the aforementioned host proteins NUP358 and CPSF6, which have been invoked in HIV-1 PIC nuclear import, may play important roles in the inhibition of HIV-1 infection by MxB.

Here in this study, we provided evidence that $\mathrm{MxB}$ binds NUP358 and disrupts the association of HIV-1 CA and NUP358, leading to reduced nuclear import of PIC and viral replication. Importantly, MxB does not inhibit
PIC nuclear import per se; instead, it hinders PIC nuclear import only when it binds to PIC collaboratively with CPSF6. Moreover, our findings were consistent with a model in which flexible use of nuclear import pathways dependent on several NUPs by HIV-1 and that CPSF6 facilitated NUP358-dependent PIC nuclear import. However, CPSF6 became an unfavorable factor to the interaction between HIV-1 CA and NUP358 when MxB is stably expressed. Binding of CPSF6 to HIV-1 CA, therefore, determined the ability of $\mathrm{MxB}$ to inhibit HIV-1 nuclear import.

\section{Results \\ MxB binds to NUP358 and disrupts NUP358 association with HIV-1 viral cores}

$\mathrm{MxB}$ has been reported to have pleiotropic effects on HIV-1 uncoating, nuclear import, as well as integration [18]. To identify the exact process during HIV-1 infection affected by $\mathrm{MxB}$, we stably expressed $\mathrm{MxB}$ in human HeLa cells, primary macrophages and primary $\mathrm{CD}_{4}^{+}$ $\mathrm{T}$ cells, tested the ability of these cells to restrict HIV-1 (Additional file 1). In agreement with previous reports, $\mathrm{MxB}$ potently reduced HIV-1 infection in all tested cells. In addition, 2-long terminal repeat (LTR) circular DNA (a marker for viral cDNA nuclear localization) and integrated (provirus) DNA were decreased in cells stably expressing $\mathrm{MxB}$, though the second strand transfer products of Late RT did not differ as compared to the control cells. These data indicated that $\mathrm{MxB}$ might restrict the nuclear import and integration of HIV-1 but not reverse transcription.

Previous work had demonstrated that there was a significant degree of colocalization between $\mathrm{MxB}$ and several nucleoporins, such as NUP98 and NUP358 [2, 13, 38]. Immuno-fluorescent staining of wild-type $\mathrm{MxB}$ protein revealed that it mainly localized along the nuclear rim and also in a punctate cytoplasmic pool in transfected HeLa cells (Additional file 1a). To investigate how $\mathrm{MxB}$ affects HIV-1 nuclear import, we first examined the association of $\mathrm{MxB}$ with one of the most important nucleoporins, NUP358, which is responsible for recruiting HIV-1 PIC at the cytoplasmic side of NPC during nuclear import [24]. Hemagglutinin (HA)-tagged wildtype $\mathrm{MxB}$ or non-antiviral short isoform of $\mathrm{MxB}$ that lacks the NLS $\left(\mathrm{MxB}_{\Delta \mathrm{NLS}}\right)$ were expressed in 293T cells. Then co-immunoprecipitation analyses were performed by endogenous NUP358 immunoprecipitation, and immunoblot detection of associated HA-tagged proteins. We found that MxB bound NUP358 while weaker binding between $\mathrm{MxB}_{\triangle \mathrm{NLS}}$ and NUP358 (Fig. 1a). Indirect immuno-fluorescence analysis of transiently transfected HeLa cells revealed that wild-type $\mathrm{MxB}$ localized to the nuclear membrane and was also found in cytoplasm as 


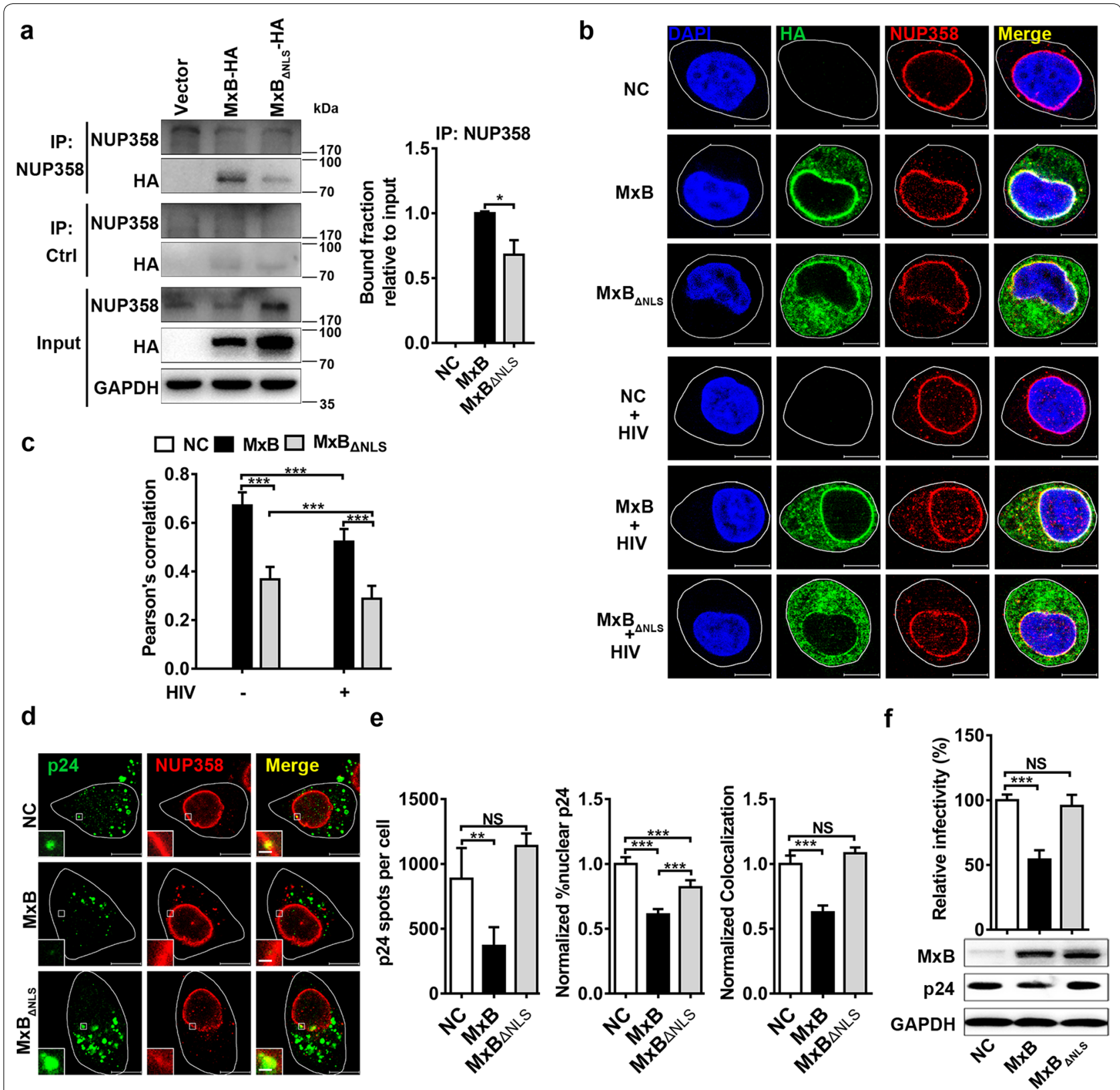

Fig. 1 MxB binds to NUP358 and disrupts NUP358 association with HIV-1 viral cores. a The interaction between NUP358 and MxB was identified by co-immunoprecipitation analysis in 293T cells. Similar results were obtained in 3 independent experiments, and the standard deviation for the bound fraction relative to input was shown. $\mathbf{b}$ HeLa cells were transfected with plasmid expressing wild-type MxB-HA or MxB ${ }_{\triangle N L S}{ }^{-H A}$ protein. $48 \mathrm{~h}$ after transfection, cells were infected with VSV-G pseudotyped HIV-1 luciferase reporter virus or not. Cells were fixed $6 \mathrm{~h}$ following infection and stained for MxB (green), NUP358 (red) using HA- or NUP358-specific antibodies, respectively. Cell nuclei were stained by DAPI (blue). Scale bar, $10 \mu \mathrm{m}$. c Pearson correlation coefficient values for colocalization of MxB with NUP358 were analysed by image analysis software in about 40 cells. Data was representative of 3 independent experiments. $\mathbf{d}$ HeLa cells were transfected with plasmid expressing wild-type MxB-HA or MxB $\triangle$ NLS ${ }^{-H A}$ protein. $48 \mathrm{~h}$ after transfection, cells were infected with VSV-G pseudotyped HIV-1 luciferase reporter virus. Cells were fixed $6 \mathrm{~h}$ post infection and stained for HIV-1 capsid protein p24 (green), NUP358 (red) and DAPI (blue) for cell nuclei. Scale bar, 10 mm. e P24 spots, the percentage of the p24 signals detected in the nucleus and the percent p24 colocalizing with NUP358 in HeLa cells was counted in about 40 cells. Data were representative of 3 independent experiments. $\mathbf{f H e L a}$ cells were transfected with plasmid expressing wild-type MxB-HA or MxB ${ }_{\triangle N \text { IS }}$-HA protein. $48 \mathrm{~h}$ after transfection, cells were infected with VSV-G pseudotyped HIV-1 luciferase reporter virus. The infectivity was determined $48 \mathrm{~h}$ post infection. Results were a summary of 3 independent experiments. Statistical significance: NS: not significant, ${ }^{*} p<0.05,{ }^{* *} p<0.01$ and ${ }^{* * *} p<0.001$ 
(See figure on next page.)

Fig. 2 MxB interrupts the NUP358-mediated HIV-1 nuclear import and viral replication. a HeLa-Ctrl and HeLa-MxB cells were transfected with siRNA targeting NUP358 (siNUP358), NUP98 (siNUP98) or negative control (siNC). $48 \mathrm{~h}$ after transfection, the expression levels of NUP358 and NUP98 were monitored by western blot. $\mathbf{b}, \mathbf{c}$ siRNA depleted cells were infected with similar amount of VSV-G pseudotyped HIV-1 luciferase reporter virus bearing either the wild-type (WT) CA or N74D CA mutant. Infectivity was determined $48 \mathrm{~h}$ post infection by luciferase assay (b) and WB analysis of p24 (c). Results were a summary of 3 independent experiments. $\mathbf{d}$ HeLa cells were transfected with plasmid expressing MxB-HA protein or empty vector. $48 \mathrm{~h}$ after transfection, cells were infected with similar amount of HIV-1 ${ }_{\mathrm{WT}}$ or HIV-1 ${ }_{\mathrm{N} 74 \mathrm{D}}$. Cells were fixed $6 \mathrm{~h}$ post infection and stained for HIV-1 capsid protein p24 (green), NUP358 (red) and DAPI (blue) for cell nuclei. Scale bar, $10 \mu \mathrm{m}$. e P24 spots, the percentage of the p24 signals detected in the nucleus and the percent p24 colocalizing with NUP358 in HeLa cells was counted in about 40 cells. Data were representative of 3 independent experiments. Statistical significance: NS: not significant, ${ }^{*} p<0.05,{ }^{* *} p<0.01$ and ${ }^{* * *} p<0.001$

the same seen in Additional file 1a. There was a significant degree of colocalization between MxB and NUP358. However, deletion of the NLS resulted in cytoplasmic localization and less association with NUP358. Moreover, colocalization between MxB and NUP358 decreased after HIV-1 infection (Fig. 1b, c). To investigate whether MxB affects NUP358 association with the HIV-1 cores during infection, we assessed the extent of colocalization between viral cores and NUP358 following infection of the HeLa cells by immuno-fluorescence confocal assays (Fig. 1d). As shown in Fig. 1e, MxB reduced nuclear CA accumulation and disrupted NUP358-CA colocalization, which indicates MxB may competitively block NUP358 interactions with $\mathrm{CA}$. However, $\mathrm{MxB}_{\Delta \mathrm{NLS}}$ did not affect the colocalization between viral cores and NUP358 (Fig. 1e), and failed to inhibit HIV-1 infection (Fig. 1f). Thus, the NLS might be critical for MxB to reduce the association between NUP358 and PIC.

These data together indicated that $\mathrm{MxB}$ might sequester NUP358 and disrupt PIC recruitment, thus impeding the nuclear import of PIC.

\section{MxB interrupts the NUP358-mediated HIV-1 nuclear import and viral replication}

Since genetic and biochemical evidence suggests that HIV- 1 CA is the target of $\mathrm{MxB}$ during infection [10, $17,40], \mathrm{HIV}-1$ may mutate its CA to escape from $\mathrm{MxB}$ restriction. During the nuclear import of the viral genome, HIV-1 CA plays a critical part through a series of interactions with multiple host cell factors [21, 41, 42]. HIV-1 CA mutations, including N74D mutation, have been shown to change the requirement for specific nucleoporins (for example, NUP358, NUP98, NUP153 and NUP155) during HIV-1 nuclear import, and to alter the distribution of sites at which HIV-1 DNA integrates into host chromosomes [20, 27, 34-37, 43]. Moreover, $\mathrm{MxB}$ localizes to nuclear pores and inhibits the nuclear entry step of HIV-1 infection. Therefore, we wondered whether NUPs also affected sensitivity to inhibition by MxB. Initially, we challenged HeLa-Ctrl and HeLa-MxB cells with VSV-G pseudotyped HIV-1 bearing either the wild-type (WT) CA (HIV-1 $\left.{ }_{\mathrm{WT}}\right)$ or N74D CA mutant
$\left(\mathrm{HIV}-1_{\mathrm{N} 74 \mathrm{D}}\right)$. In agreement with previous publications, HIV- $1_{W_{T}}$ infection was inhibited by MxB, while N74D mutation eliminated sensitivity to $\mathrm{MxB}$ (Additional file 2). Then we depleted the NUP358 or NUP98 of HeLa cells by transient transfection of specific siRNAs (Fig. 2a). Reductions in NUP358 or NUP98 led to a visible reduction of HIV-1 ${ }_{\mathrm{WT}}$ infection in HeLa-Ctrl cells (Fig. 2b, c, blank columns). Notably, reductions in NUP358 or NUP98 did not reduce HIV- $1_{\mathrm{WT}}$ infection to a significantly lower level in HeLa-MxB cells (Fig. 2b, c, black columns). By contrast, infection with HIV-1 $1_{\mathrm{N} 74 \mathrm{D}}$ was minimally affected by NUP358 or NUP98 depletion both in HeLa-Ctrl and HeLa-MxB cells. Moreover, silencing of NUP358 and NUP98 each abolished or reduced the magnitude of $\mathrm{MxB}$ inhibition of $\mathrm{HIV}-1_{\mathrm{WT}}$ infection. These data collectively implied the dependence of $\mathrm{HIV}-1_{\mathrm{WT}}$ but not HIV-1 ${ }_{\text {N74D }}$ on NUP358 and NUP98 for viral infection and $\mathrm{MxB}$ restriction, or stated differently, $\mathrm{MxB}$ inhibits the NUP358/NUP98-dependent nuclear import pathway exploited by HIV-1 $1_{\mathrm{WT}}$.

To further understand the antiviral mechanism of $\mathrm{MxB}$, we next investigated whether $\mathrm{MxB}$ affected nuclear import of PIC during HIV-1 $1_{\mathrm{N} 74 \mathrm{D}}$ infection. Immuno-fluorescence confocal assays showed that nuclear $\mathrm{CA}_{\mathrm{N} 74 \mathrm{D}}$ and colocalization of NUP358 with $\mathrm{CA}_{\mathrm{N} 74 \mathrm{D}}$ did not reduce in HeLa-MxB cells compared to HeLa-Ctrl cells 6 h post HIV- $1_{\text {N74D }}$ infection (Fig. 2d, e). Notably, in HeLa-Ctrl cells, HIV-1 $1_{\mathrm{N} 74 \mathrm{D}}$ had similar nuclear CA accumlation but less NUP358-CA colocalization as compared to HIV-1 $1_{\text {WT }}$ $6 \mathrm{~h}$ post infection (Fig. 2e, blank columns), the HIV-1 ${ }_{\mathrm{N} 74 \mathrm{D}}$ also exhibited similar replication level as HIV-1 $1_{\mathrm{WT}}$ did at $48 \mathrm{~h}$ post infection (Additional file 2). Similar nuclear $\mathrm{CA}_{\mathrm{N} 74 \mathrm{D}}$ accumulation but lower NUP358-CA $\mathrm{A}_{\mathrm{N} 74 \mathrm{D}}$ colocalization probably suggested that HIV- $1_{\mathrm{N} 74 \mathrm{D}}$ has NUP358-independent alternative pathway to effectively enter the nucleus [44]. Intriguingly in HeLa-MxB cells, nuclear CA accumulation and NUP358-CA colocalization increased upon $\mathrm{HIV}-1_{\mathrm{N} 74 \mathrm{D}}$ infection as compared to $\mathrm{HIV}-1_{\mathrm{WT}}$ (Fig. 2e, black columns), indicating more efficient NUP358 recruitment and nuclear import of $\mathrm{PIC}_{\mathrm{N} 74 \mathrm{D}}$ as compared to HIV-1 $1_{\mathrm{WT}}$ in the presence of $\mathrm{MxB}$. 

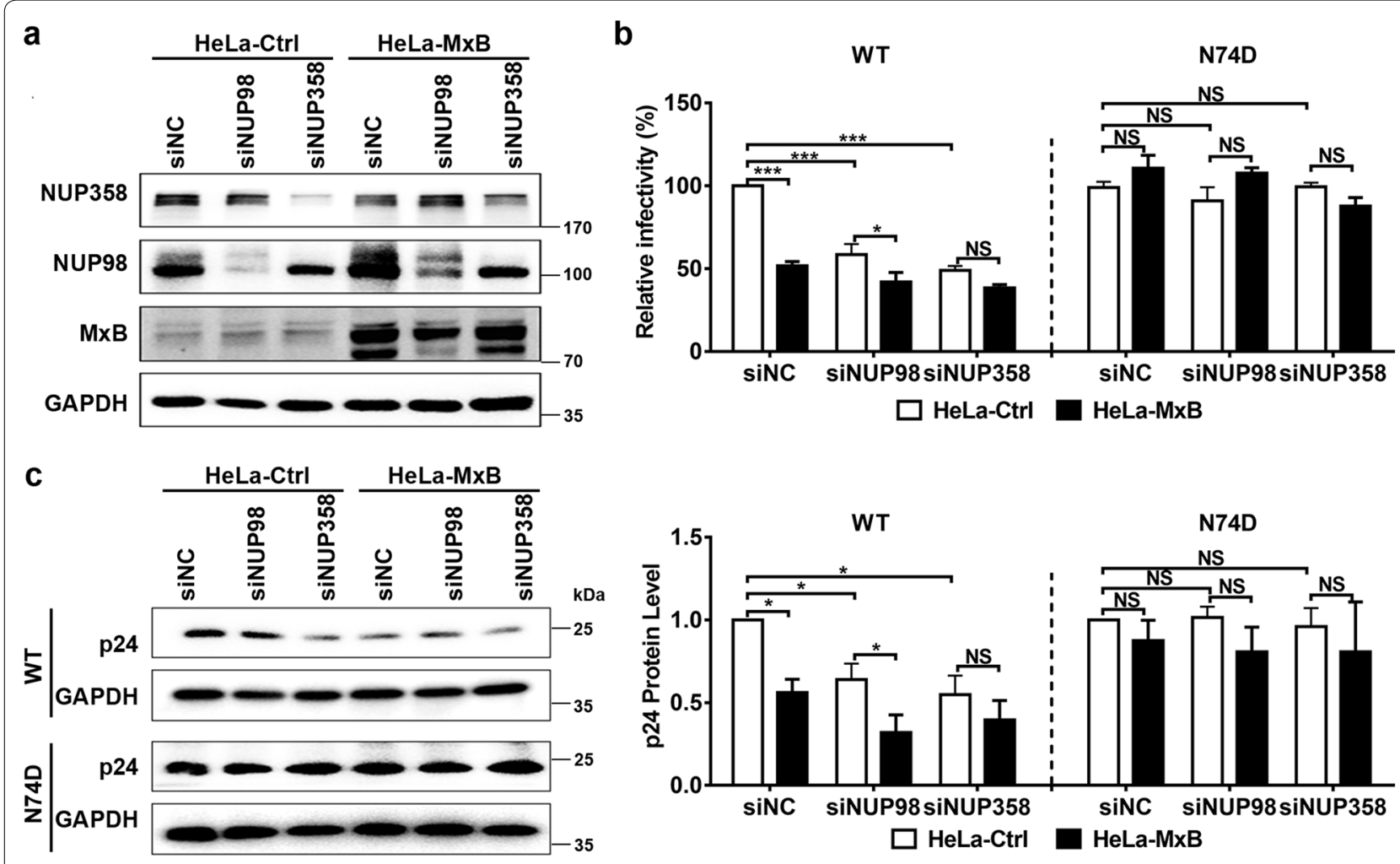

d
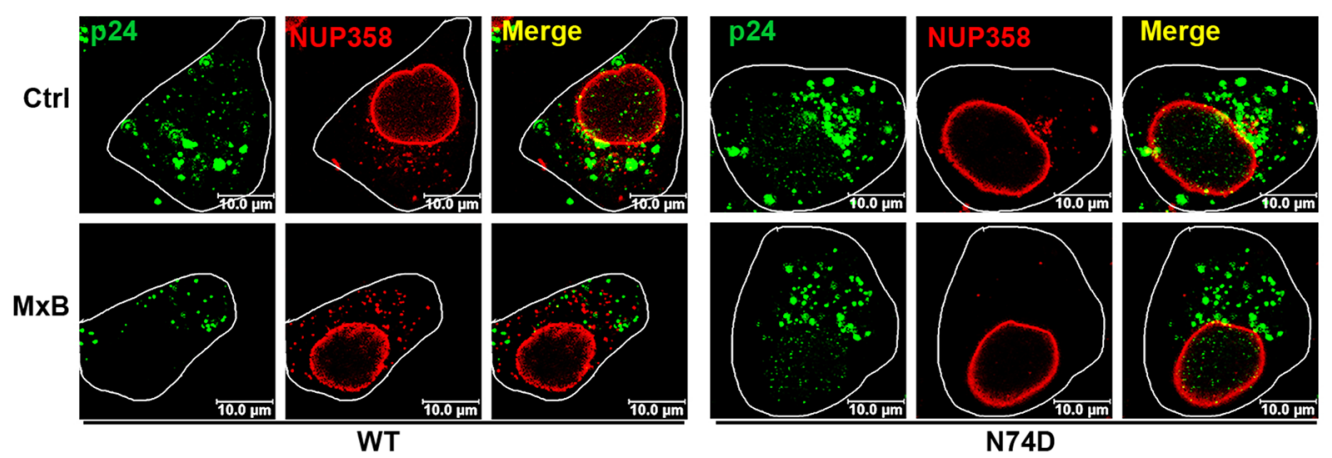

e
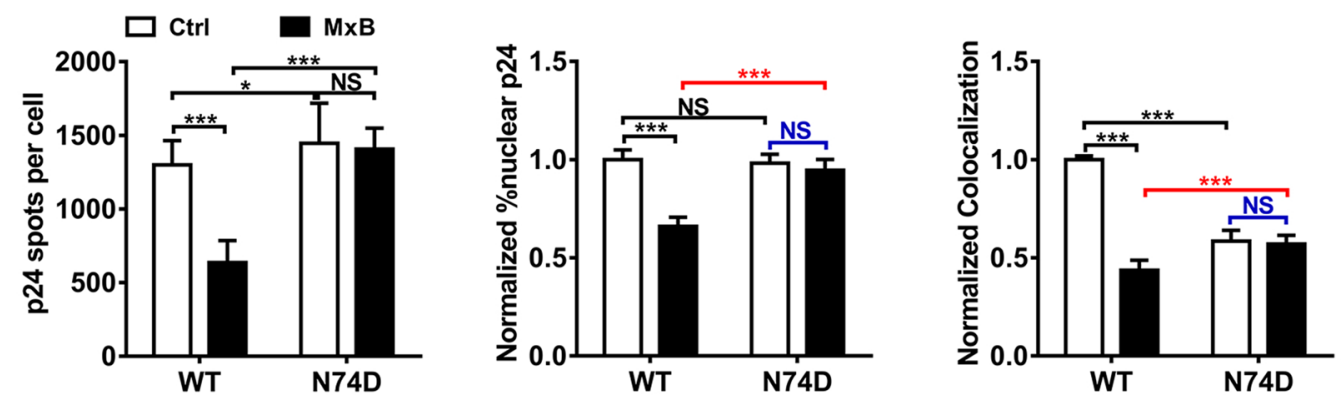

These data together suggested that the specific association between HIV-1 $1_{\text {WT }}$ viral cores and NUP358 could be interrupted by $\mathrm{MxB}$, supported a potential mechanism that $\mathrm{MxB}$ reduced the PIC anchoring to the NUP358, leading to the inhibition of HIV-1 $1_{\mathrm{WT}}$ nuclear import. 


\section{CPSF6 cooperates with MxB to inhibit the association of NUP358 with HIV-1 cores}

How do we explain the above phenotypes of $\mathrm{MxB}$ on HIV-1 $1_{\text {N74D }}$ ? The N74D mutation abolished CA binding to the capsid cofactor CPSF6, altered the dependence on nuclear pore protein and eliminated the ability of $\mathrm{MxB}$ to restrict HIV-1. It has been affirmed that CPSF6 facilitates the interaction between HIV-1 cores and NUP358 [28], consistently as seen in our observation, association of NUP358 with HIV-1 $1_{\mathrm{N} 74 \mathrm{D}}$ viral cores was remarkably weaker than HIV-1 $1_{\text {WT }}$ viral cores (Fig. 2e). These facts suggested that CPSF6 might play a role in the restriction of MxB to HIV-1. We next measured HIV-1 infectivity in HeLa cells overexpressing MxB simultaneously silenced for the expression of CPSF6 (Fig. 3a). Similar to N74D mutation, knockdown of CPSF6 eliminated HIV-1 $1_{\mathrm{WT}}$ 's sensitivity to $\mathrm{MxB}$ (Fig. 3b). Reduced 2-LTR circles and integrated DNA were also rescued in HeLa-MxB cells when CPSF6 was knocked down (Fig. 3c). These experiments indicated that endogenous CPSF6 was required for the ability of $\mathrm{MxB}$ to inhibit HIV-1 nuclear import.

We then measured the colocalization of NUP358-CA in HeLa-MxB cells under CPSF6 RNAi (Fig. 3d, e). MxB did not affect the nuclear CA accumulation or NUP358-CA colocalization when the endogenous CPSF6 was knocked down (Fig. 3f, siCPSF6 groups). Notably, similar to N74D mutation, CPSF6 knockdown decreased colocalization between HIV-1 cores and NUP358 in HeLa-Ctrl cells (Fig. 3f, blank columns), which was in accordance with the report that CPSF6 facilitated the interaction between HIV-1 cores and NUP358 [28]. However, when knockdown of CPSF6 in HeLa-MxB cells, nuclear CA or NUP358-CA colocalization was not reduced, but unexpectedly increased to similar level of that in HeLaCtrl cells (Fig. 3f, black columns). This observation suggested not only that MxB impaired HIV-1 nuclear import dependently on CPSF6, but also that CPSF6 exerted opposite effect on HIV-1 nuclear import with or without $\mathrm{MxB}$ expression.

We also measured HIV-1 infectivity in HeLa cells overexpressing both $\mathrm{MxB}$ and CPSF6. MxB retained the antiviral activity under CPSF6 overexpression. Unexpectedly, overexpressed CPSF6 did not affect HIV-1 infection in HeLa-Ctrl cells, but when we overexpressed CPSF6 in HeLa-MxB cells, 2-LTR circles and integrated DNA was reduced, although viral replication was not affected (Additional file 3).

These results manifested that CPSF6 cooperates with $\mathrm{MxB}$ to inhibit the association of NUP358 with HIV-1 cores. Moreover, it appeared that CPSF6 is able to exert two different effects on HIV-1 nuclear import: a stimulatory effect in the absence of $\mathrm{MxB}$ and an inhibitory effect under the condition of MxB location at NPCs. Probably due to steric hindrance, CPSF6 and MxB binding to CA simultaneously disrupts NUP358-CA colocalization thus reduces PIC nuclear import. Therefore, CA N74D mutation (Fig. 2e), or knocking down CPSF6 (Fig. 3f), both would release CPSF6 from PIC, facilitate NUP358$\mathrm{CA}$ interaction and PIC nuclear import, with $\mathrm{MxB}$ at the NPCs. In other words, CPSF6 bound to CA might cooperate with $\mathrm{MxB}$ to impede PIC nuclear import and restrict $\mathrm{HIV}-1$ replication.

\section{CPSF6 is essential for MxB to inhibit HIV-1 nuclear import in HIV-1 target cells}

In an attempt to provide additional evidence for the role of CPSF6 in MxB anti-HIV-1 activity using a more physiologically relevant model, we tested the effect of knockdown of CPSF6 in primary cells from 3 healthy donors. We challenged primary macrophages (Fig. 4a) and primary $\mathrm{CD}_{4}^{+} \mathrm{T}$ cells (Fig. 4b) stably expressing $\mathrm{MxB}$ simultaneously silenced for the expression of CPSF6 with HIV-1 $1_{\mathrm{Bal}}$ or HIV-1 $1_{\mathrm{NL} 4-3}$ respectively. Knockdown of CPSF6 affects HIV-1's sensitivity to MxB. Reduced 2-LTR circles and integrated DNA were also rescued in $\mathrm{MxB}$ expressing cells when CPSF6 was knocked down. These data were in concordance with the data obtained in HeLa cell lines, and confirmed the contributions of CPSF6 to $\mathrm{MxB}$ restriction of HIV-1 infection.

Overall, these experiments indicated that endogenous CPSF6 was required for the ability of $\mathrm{MxB}$ to inhibit the nuclear accumulation and integration of HIV-1 reverse transcripts. In other words, CPSF6 facilitated MxB restriction of HIV-1 nuclear import.

\section{PF74 affects the restriction of MxB to HIV-1}

Since release of CPSF6 by CA N74D mutation or CPSF6 RNAi eliminated MxB's anti-HIV-1 function, we further tested the effects of PF-3450074 (PF74), a small inhibitor that directly binds the HIV-1 CA at a site also utilized by host cell proteins CPSF6 and NUP153 [33, 45]. Accordingly, the interaction of CPSF6 with HIV-1 CA could be competitively blocked by PF74 both in vitro and in vivo [33, 45]. Moreover, PF74 did not affect the binding of MxB to HIV-1 capsid [14]. As mentioned above, CPSF6 knockdown and CA mutation (N74D) drastically altered the function of $\mathrm{MxB}$ on $\mathrm{HIV}-1$. We therefore postulated that the interruption of HIV-1 CA-CPSF6 interactions by PF74 may have a similar effect on the function of $\mathrm{MxB}$ to the block imposed by CPSF6 RNAi and CA mutation (N74D).

We then investigated the effects of PF74 on the restriction of $\mathrm{MxB}$ to $\mathrm{HIV}-1$. HIV-1 was preincubated with PF74 $(1 \mu \mathrm{M})$ or carrier DMSO $(0.1 \%)$ and then added to HeLa cells. PF74 blocked HIV-1 $1_{\mathrm{WT}}$ infection in HeLaCtrl cells, while HIV-1 $1_{\mathrm{N} 74 \mathrm{D}}$ appeared to be less sensitive 

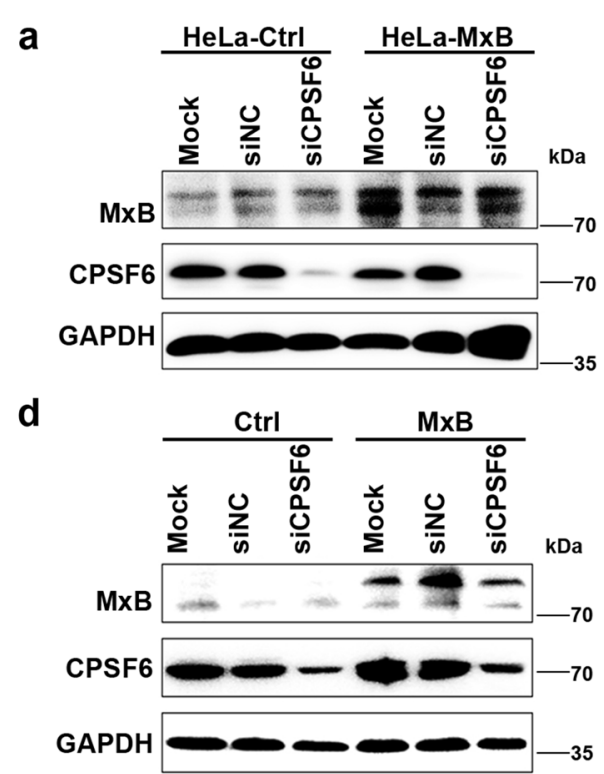

e
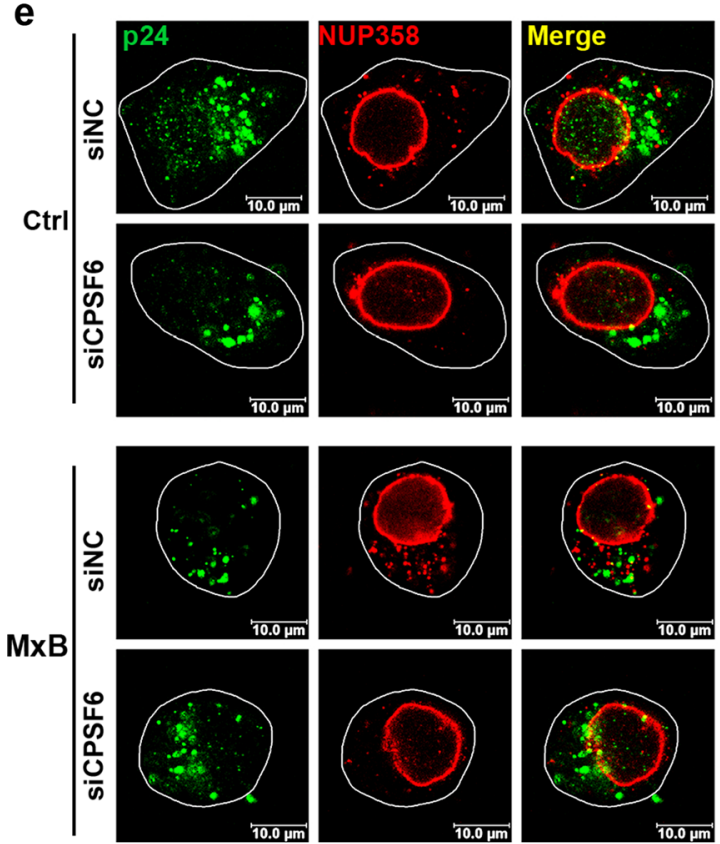

Fig. 3 CPSF6 cooperates with MxB to inhibit the association of NUP358 with HIV-1 cores. a HeLa-Ctrl and HeLa-MxB cells were not transfected (Mock) or transfected with siRNA targeting CPSF6 (siCPSF6) or negative control (siNC). $48 \mathrm{~h}$ after transfection, the expression levels of CPSF6 and MxB were monitored by western blot. $\mathbf{b}$ siRNA depleted cells were incubated with HIV-1 ${ }_{\text {WT}}$, infectivity was determined $48 \mathrm{~h}$ post infection. $\mathbf{c}$ siRNA depleted cells were incubated with HIV-1 WT $_{\text {, }}$ PCR analysis of HIV-1 Late RT DNA, 2-LTR circle DNA and integrated DNA was preformed $24 \mathrm{~h}$ post infection. Results were a summary of 3 independent experiments. d, e HeLa cells were first transfected with siRNA targeting CPSF6 (siCPSF6) or negative control (siNC), a second transfection was performed $24 \mathrm{~h}$ later with plasmid expressing MxB-HA protein or empty vector. Western blot for CPSF6 and MxB $96 \mathrm{~h}$ following siRNA transfection was shown (d). $72 \mathrm{~h}$ after the first siRNA transfection, cells were infected with HIV-1 wT. Cells were fixed $6 \mathrm{~h}$ post infection and stained for HIV-1 capsid protein p24 (green), NUP358 (red) and DAPI (blue) for cell nuclei. Scale bar, $10 \mu \mathrm{m}$ (e).f P24 spots, the percentage of the p24 signals detected in the nucleus and the percent p24 colocalizing with NUP358 in HeLa cells was counted in about 40 cells. Data were representative of 3 independent experiments. Statistical significance: NS: not significant, ${ }^{*} p<0.05,{ }^{* *} p<0.01$ and ${ }^{* * *} p<0.001$ 
(See figure on next page.)

Fig. 4 CPSF6 is essential for MxB to inhibit HIV-1 nuclear import in target cells. Primary MDMs (a) and CD4 ${ }^{+} \mathrm{T}$ cells $(\mathbf{b})$ isolated from three independent donors were transduced with concentrated lentivirus overexpressing MxB or a control lentivirus (Ctrl) for $72 \mathrm{~h}$, then cells were transfected with CPSF6 siRNA (siCPSF6) either negative control (siNC). $24 \mathrm{~h}$ after siRNA transfection, cells were challenged with $\mathrm{HIV}-1_{\text {Bal }}$ or HIV-1 NL4-3 $_{\text {. }}$ The level of of MxB, CPSF6, Gag and HIV-1 DNA was determined $48 \mathrm{~h}$ post infection. The mean \pm SD of three technical replicates were shown for each donor

to PF74 since N74D mutation in CA reduced the affinity of PF74 to CA as reported in previous study [33]. Surprisingly, MxB did not exhibit a synergistic effect on HIV-1 restriction after PF74 treatment but slightly rescued HIV-1 infection (Fig. 5a). Confocal analysis reinforced that $\mathrm{MxB}$ did not block nuclear $\mathrm{CA}$ accumulation and NUP358 association with viral cores in the presence of PF74 (Fig. 5b, c). It was intriguing that PF74 treatment slightly elevated NUP358 association with viral cores, but reduced nuclear CA accumulation in HeLa cells overexpressing $\mathrm{MxB}$ (Fig. 5c, black columns). Since PF74 has been reported to stabilize HIV-1 capsid [45] but did not affect the binding of MxB to capsid [14]. Thus, PF74 treatment could allow MxB-PIC interaction but stabilized the capsid and stalled PIC on NUP358, resulting increased NUP358-PIC colocalization but reduced PIC nuclear import.

Taken together, these findings reveal a pleiotropic role of HIV-1 CA-CPSF6 interaction in contributing to MxB restriction of HIV-1, since PF74 replacement of CPSF6 abrogates MxB-mediated HIV-1 restriction, as well as MxB-engaged disruption of NUP358-CA association.

\section{Discussion}

After reverse transcription, HIV-1 PIC hijack the host cellular components and nuclear transport machinery for transportation to the nucleus [20,37]. MxB has been implicated in cellular functions to regulate cytoplasmicnuclear transport [1]. It was also reported to restrict HIV infection, but the molecular mechanism underlying the involvement of $\mathrm{MxB}$ in viral replication was unclear. In this study, we identified a function of MxB in HIV-1 nuclear import insofar as it impeded the NUP358-mediated HIV-1 PIC nuclear import and viral replication with help of CPSF6.

$\mathrm{MxB}$ has previously been proposed to suppress HIV-1 infection by inhibiting the nuclear import of viral PIC, a view supported by that the active $78 \mathrm{kDa}$ isoform of $\mathrm{MxB}$ mainly localized along the nuclear rim. NUP358, a large multi-domain protein associated with the cytoplasmic side of the NPC, can interact with HIV-1 CA via its cyclophilin domain driving HIV-1 uncoating, and facilitate HIV-1 nuclear entry and integration. Recent study has found that $\mathrm{MxB}$ expression did not detectably affect the interaction between NUPs and CA tubes in vitro, including NUP358 [46]. Because the CA tubes were in large excess in that study, they did not exclude the possibility that $\mathrm{MxB}$ could inhibit infection by competitively inhibiting interactions between CA and NUPs. In our study, we measured the intensity of NUP358 staining associated with individual viral cores in HeLa cells infected with HIV-1 $1_{\mathrm{WT}}$ or $\mathrm{HIV}-1_{\mathrm{N} 74 \mathrm{D}}$ and found that MxB could inhibit the association of NUP358 with HIV-1 $1_{\text {WT }}$ CA but not HIV-1 ${ }_{\mathrm{N} 74 \mathrm{D}}$. Therefore we proposed that $\mathrm{MxB}$ disrupted the association of HIV-1 CA with NUP358, leading to reduced nuclear import of $\mathrm{HIV}-1_{\mathrm{WT}}$ PIC and viral replication. We provide evidences that: (1) $\mathrm{MxB}$ binds NUP358; (2) NLS is crucial for MxB to disrupt NUP358$\mathrm{CA}$ interaction and viral replication; (3) $\mathrm{MxB}$ restricts the NUP358-mediated HIV-1 nuclear import and viral replication (Figs. 1 and 2).

Mutations in CA permit escape from MxB-mediated restriction, including at positions $\mathrm{H} 87, \mathrm{G} 89$ and $\mathrm{P} 90$ (the CypA binding loop), N74 and N57 (the CPSF6 binding site), and T210 and G208 (in the C-terminal domain of CA) $[10,13,40,47,48]$. However, such mutant CA proteins retain the ability to interact with $\mathrm{MxB}$ in vitro, suggesting the existence of $\mathrm{MxB}$ co-factors required for $\mathrm{MxB}$ mediated viral restriction. Since escaped mutations are mapped to different domains of $\mathrm{CA}$, the restriction mechanism of $\mathrm{MxB}$ is most likely multifactorial and relies on multiple interactions. Previous study has demonstrated that the antiviral activity of $\mathrm{MxB}$ is dependent upon an interaction between the HIV-1 CA and a host factor cyclophilin (CypA) [4]. In our study, we demonstrated that the antiviral activity of $\mathrm{MxB}$ is dependent upon an interaction between HIV-1 CA and CPSF6. We used three methods to dissociate CPSF6 from PIC: CA N74D mutation (Fig. 2), CPSF6 RNAi (Figs. 3 and 4) and PF74 compound treatment (Fig. 5), and then compared NUP358-CA colocalization, HIV-1 nuclear import and replication. MxB did not inhibit NUP358-CA colocalization, HIV-1 nuclear import and replication at all three conditions, strongly suggesting CPSF6 as a co-factor required for $\mathrm{MxB}$ inhibition of HIV-1. Interestingly, NUP358-CA colocalization increased in HeLa-MxB cells at all three conditions while decreased in HeLa-Ctrl cells, strongly indicating a converse effect of CPSF6 on NUP358-CA colocalization depending on MxB locates at the nuclear pore or not. CPSF6 might play two opposite roles: one is to help PIC usurping NUP358 as a positive factor [27, 28]; the other is to stabilize CA structure 

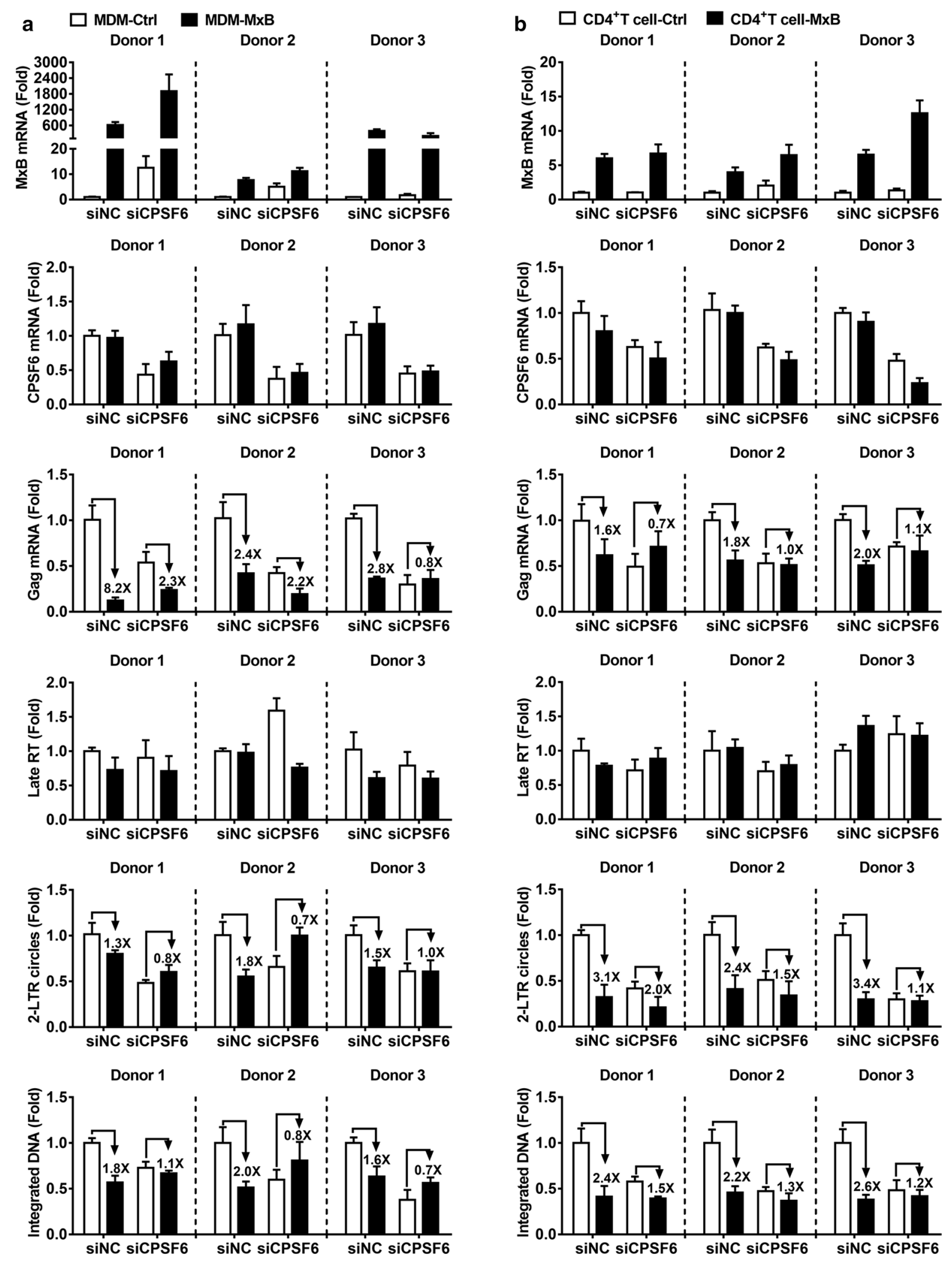


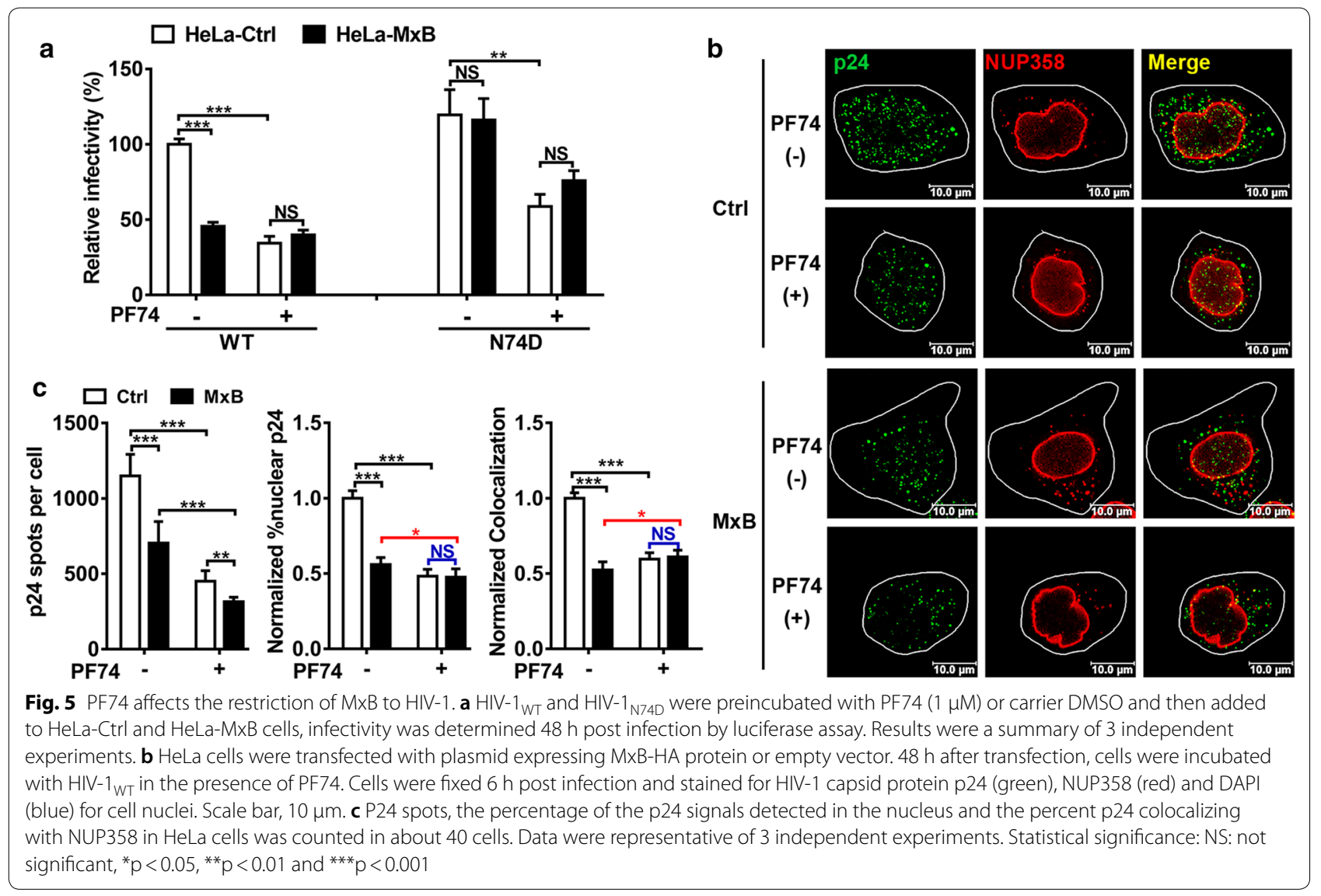

to hamper PIC nuclear import as a negative factor [32]. Perhaps for this reason, CPSF6 has a completely opposite effect on NUP358-CA colocalization in the presence or absence of MxB. In the absence of MxB, CPSF6 binding to CA helps PIC usurping NUP358 to facilitate PIC nuclear import; but in the presence of MxB, CPSF6 stabilizes CA structure to hamper PIC nuclear import. Binding of CPSF6 to PIC facilitates NUP358-mediated PIC nuclear import without $\mathrm{MxB}$, but $\mathrm{MxB}$ and CPSF6 together prevent NUP358-mediated PIC nuclear import and viral replication.

Recent studies suggest that nuclear pore heterogeneity influences the antiviral activity of $\mathrm{MxB}$ and multiple components of the nuclear pore complex interact with the amino-terminus of $\mathrm{MxB}$ to facilitate HIV-1 restriction $[39,46]$. Interestingly, several NUP-dependent pathways are variably exploited by HIV-1 to target host DNA in a cell-type, cell-cycle, CypA and CA-sequence dependent manner, and are differentially inhibited by $\mathrm{MxB}$. Thus, depending on which nuclear entry pathway incoming viral capsids choose, $\mathrm{MxB}$ is either a potent or a weak restriction factor. Of note, $\mathrm{MxB}$ can similarly control the nuclear import of host cell proteins that use the same pathways as HIV-1 [46]. The pathways through which nuclear import of HIV-1 proceeds remains unclear, but both CypA and CPSF6 can regulate the utilization of NUPs (including NUP358 and NUP153) to impact PIC nuclear entry [23, 27, 28], in this case, binding of CypA and CPSF6 to CA promotes a NUP358-dependent nuclear import, which is blocked by MxB.

In conclusion, we provide a hypothesis that during natural HIV-1 infection, CPSF6 binds to HIV-1 CA, facilitating CA binding to NUP358, thus helps PIC recruitment to NPC (Fig. 6a). Subsequently, MxB, which locates at the nuclear pore, binds NUP358 as well as HIV-1 CA, thereby influencing viral capsid interaction with NUP358, reducing PIC nuclear import and viral replication (Fig. 6b). However, in the case of $\mathrm{HIV}-1_{\mathrm{N} 74 \mathrm{D}}$ infection, the CA mutation retains $\mathrm{MxB}$ binding but rejects CPSF6 binding, MxB loses its antiviral function in the absence of CPSF6 (Fig. 6c). Our study thus showed that MxB restriction of HIV-1 replication required CPSF6 binding to CA. The contribution of CPSF6 to MxB's restriction of HIV-1 nuclear import might be due to a direct effect of CPSF6 on the association of NUP358 with HIV-1 CA. These might uncover a novel layer toward understanding the poorly defined MxB's antiviral mechanism during nuclear import. 


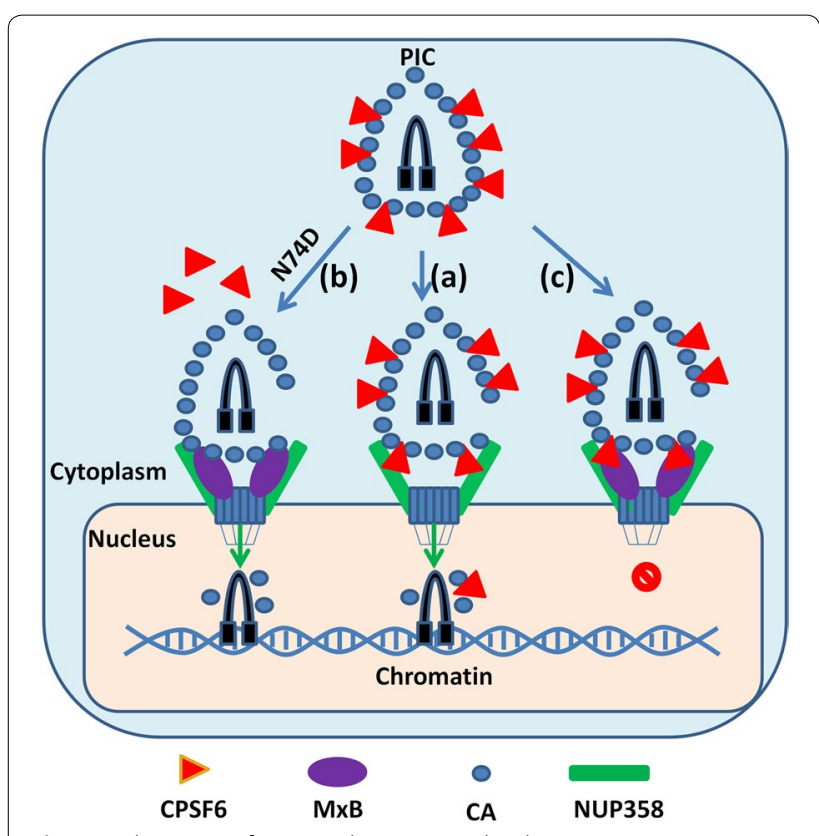

Fig. 6 Schematic of MxB and CPSF6 involved in HIV-1 pre-integration complex nuclear import. a During HIV-1 pre-integration complex (PIC) nuclear import, CPSF6 (red) binds to HIV-1 CA (blue) and facilitates PIC nuclear import by assisting interaction of PIC and NUP358 (green). b MxB (purple) locates at the nuclear envelope, binds with NUP358, grabs HIV-1CA to form CPSF6-PIC-MxB complex and disrupts NUP358-PIC interaction, leading to lower nuclear import efficiency. $\mathbf{c}$ In the absence of CPSF6 binding to HIV-1 CA, MxB retains the ability to bind to CA but lose antiviral activity

\section{Conclusions}

Our work showed that MxB impedes the NUP358-mediated HIV-1 nuclear import and viral replication cooperatively with CPSF6.

\section{Methods}

\section{Plasmids and viral vectors}

Human MxB (NM_002463.1) lentiviral vector (pLVMxB-EF1-GP), lentiviral packaging plasmids including envelope expressing plasmid psPAX2 and VSV-G envelope expressing plasmid pMD2.G were purchased from Fitgene. CPSF6 (NCBI Reference Sequence: NP_008938.2) fused to N-terminal FLAG epitope was cloned into the pCMV-Tag2B vector (Clontech) using BamHI and XhoI site. Wild type or mutant $\mathrm{MxB}$ fused to C-terminal HA epitope was cloned in the pCMV-C-HA vector (Clontech) using BamHI and XhoI site.

The HIV-1 NL4-3 molecular clone and HIV-Luc construct (pNL4-3-Luc-R-E-) were obtained from the NIH AIDS reagent program. The N74D point mutation was created by recombinant PCR site directed mutagenesis of the Gag in the vector pNL4-3. The complete viral fragment was sequenced to confirm mutation and exclude additional mutations. Mutant BssHII-ApaI fragment was recloned into pNL4-3 and HIV-Luc constructs and mutation was confirmed by sequence analysis.

\section{Cell lines}

Human 293T cells and human HeLa cells were grown in DMEM supplemented with $10 \%$ fetal bovine serum (FBS) (Gibco) and 1\% (w/v) penicillin/streptomycin. To achieve HeLa cells stably expressing MxB, HeLa cells were stably transduced with lentiviruses containing $\mathrm{MxB}$ and then selected by puromycin as we previously described [7]. Recombinant viruses were produced in 293T cells by cotransfecting psPAX2, pMD2.G and the pLV-CMV-EF1GP based plasmids (at a ratio of 1:1:2). The medium was replaced after $6 \mathrm{~h}$ incubation and viral particles collected at $48 \mathrm{~h}$, filtered and used directly to transduce target cells. HeLa cells were transduced with filtered supernatant in the presence of $8 \mu \mathrm{g} / \mathrm{mL}$ of polybrene (Sigma Biochemicals) for 6-8 h before media replacement. To achieve good overexpressing efficiency, cells were challenged 3-4 times with high viral inputs a few days apart and cultured for at least 7 days before selection. Transduced HeLa cells were selected in $1 \mu \mathrm{g} / \mathrm{mL}$ puromycin (Sigma) for a few days and maintained in DMEM supplemented with $10 \%$ FBS, 1\% (w/v) penicillin/streptomycin and $0.5 \mu \mathrm{g} / \mathrm{mL}$ puromycin.

Primary Monocyte-derived macrophages (MDMs) were prepared from fresh blood from healthy donors. Briefly, peripheral blood mononuclear cells (PBMCs) were isolated by Ficoll-Hypaque (Axis-Shield) density centrifugation. Monocytes were purified from PBMC on gelatin-coated surface and differentiated to macrophages by resuspending in DMEM containing 10\% FBS, 1\% (w/v) penicillin/streptomycin, and $20 \mu \mathrm{g} / \mathrm{mL}$ granulocyte macrophage colony-stimulating factor (GM-CSF). Cells were plated on culture dishes and differentiated for 8 days before performing experiments.

Primary $\mathrm{CD}^{+} \mathrm{T}$ cells were isolated from PBMCs by $\mathrm{CD}^{+} \mathrm{T}$ Cell Isolation Kit (Miltenyi Biotec) following the manufactures protocol. Activation of the cells was achieved using Dynabeads Human T-Activator CD3/ CD28 (BioLegend) and $50 \mathrm{U} / \mathrm{mL}$ recombinant IL-2 (rIL2) (Novoprotein) for $48 \mathrm{~h}$ in medium consisting of RPMI 1640 containing $10 \%$ FBS, $1 \%$ (w/v) penicillin/streptomycin. After activation, cells were maintained in medium containing $30 \mathrm{U} / \mathrm{mL}$ of rIL-2.

\section{Ethics statement}

Acquisition of the blood samples used in this study was approved by the ethics committee of Wuhan University School of Medicine (WUSM, \#14010). All donors gave written informed consent. 


\section{Virus and infection}

HIV-1 particles were produced by standard polyethylenimine (PEI) transfection of 293T cells. Vesicular stomatitis virus $\mathrm{G}$ protein (VSV-G)-pseudotyped wild-type or CA mutant firefly luciferase protein (Luc)-encoding HIV-1 stocks were prepared by co-transfection using a 3:1 ratio of provirus to pMD2.G, the culture medium was changed at $6 \mathrm{~h}$, and virus containing supernatant were collected $48 \mathrm{~h}$ post transfection, clarified by low-speed centrifugation $(300 \times g, 5 \mathrm{~min})$, and filtered through $0.45 \mu \mathrm{m}$ pore size sterile filters. Viral particles were filtered and then normalized according to HIV-1 p24 ELISA measured using p24 ELISA Kit (Zepto Metrix). For infection assays, $1 \times 10^{5}$ cells were transduced in 24-well plate in triplicate and were inoculated with virus at $37{ }^{\circ} \mathrm{C}$ for $4 \mathrm{~h}$ in the presence of $8 \mu \mathrm{g} / \mathrm{mL}$ of polybrene, after which virus containing medium was removed and replaced with media. Infectivity was measured by luciferase activity $48 \mathrm{~h}$ post synchronized infection using the Steady-Glo kit (Promega, Mannheim, Germany) or by measuring viral $\mathrm{p} 24$ protein expression.

The macrophage-tropic R5 strain HIV-1 $1_{\mathrm{Bal}}$ was obtained from the AIDS Research and Reference Program, NIH (Bethesda, MD, USA). Macrophages were infected with cell-free $\mathrm{HIV}-1_{\mathrm{Bal}}$ for $4 \mathrm{~h}$ at $37{ }^{\circ} \mathrm{C}$ in the presence of $8 \mu \mathrm{g} / \mathrm{mL}$ of polybrene. Cells were then washed three times with DMEM to remove unabsorbed virus, and fresh medium was added. Infectivity was measured $48 \mathrm{~h}$ post infection by measuring viral Gag gene expression.

The $\mathrm{T}$ cell-tropic $\mathrm{X} 4$ strain $\mathrm{HIV}-1_{\mathrm{NL} 4-3}$ was produced in $293 \mathrm{~T}$ cells by transfecting pNL4-3. The medium was replaced after $6 \mathrm{~h}$ incubation and virus containing supernatant were collected $48 \mathrm{~h}$ post transfection, clarified by low-speed centrifugation $(300 \times g, 5 \mathrm{~min})$, and filtered through $0.45 \mu \mathrm{m}$ pore size sterile filters. The amount of HIV-1 was standardized according to the concentration of the p24 antigen measured using p24 ELISA Kit. Primary $\mathrm{CD}^{+} \mathrm{T}$ cells were infected with cell-free HIV$1_{\mathrm{NL} 4-3}$ for $4 \mathrm{~h}$ at $37^{\circ} \mathrm{C}$ in the presence of $8 \mu \mathrm{g} / \mathrm{mL}$ of polybrene. Cells were then washed three times with RPMI 1640 to remove unabsorbed virus, and fresh medium was added. Infectivity was measured $48 \mathrm{~h}$ post infection by measuring viral Gag gene expression.

\section{RNAi interference}

siRNA sequences targeting NUP358, NUP98, CPSF6 has been described before [27]. siRNAs were transfected into HeLa-Ctrl and HeLa-MxB cells plated on 12-well plate using INTERFERin (Polyplus transfection) as the manufactures protocol. $24 \mathrm{~h}$ after the siRNA transfection, cells were collected and seeded on to 24-well plate for subsequent experiments a day later. Western blotting was performed to monitor knockdown efficiency of the siRNA.

\section{PF74 treatment}

PF-3450074 (PF74) was purchased from Aobious (AOBIOUS INC, MA, USA). Stock solutions of PF74 were prepared at $10 \mathrm{mM}$ in dimethyl sulfoxide (DMSO). For assays up to a $10 \mu \mathrm{M}$ final concentration, the compound was diluted to $1 \mathrm{mM}$ in DMSO and added directly to prediluted viruses to the desired final concentrations. Briefly, HeLa-Ctrl and HeLa-MxB cells were inoculated with VSV-G pseudotyped HIV-1 luciferase reporter virus bearing either the wild-type (WT) CA or N74D CA mutant. The virus was preincubated with PF74 $(1 \mu \mathrm{M})$ or carrier DMSO $(0.1 \%)$ for $30 \mathrm{~min}$ at room temperature and then added to cultures (prewashed with PBS) for 30 min at $4{ }^{\circ} \mathrm{C}$, after which the cultures were incubated at $37{ }^{\circ} \mathrm{C}$ for $4 \mathrm{~h}$, infection assays were performed $48 \mathrm{~h}$ post infection.

\section{Western blotting}

Cell lysates were prepared by lysing cells with Radio Immunoprecipitation Assay (RIPA) lysis buffer containing protease inhibitor cocktail (Roche) for $15 \mathrm{~min}$ on ice. Following incubation, lysates were spun down at $12,000 g$ for $5 \mathrm{~min}$ and supernatant was collected for western blot analysis. In brief, $5 \times$ SDS loading buffer were added to the lysed sample and incubated at $100{ }^{\circ} \mathrm{C}$ for $5 \mathrm{~min}$. Protein concentration was measured using Pierce BCA protein assay kit (Thermo Scientific) and equal amount of protein was loaded into an $8 \%$ polyacrylamide gel for SDS-polyacrylamide gel electrophoresis (SDS-PAGE). Upon separation, the proteins were transferred to PVDF membrane (Merckmillipore) using Trans-Blot Turbo transfer system (Bio-Rad). The primary antibodies used were mouse anti-MxB (Santa cruze, sc-271527,1:500), mouse anti-CPSF6 (Santa cruze, sc-376228, 1:500), rabbit anti-NUP358 (Abcam, ab64276, 1:2000), rabbit antiNUP98 (Abcam, ab50610, 1:2000), mouse anti-p24 (Abcam, ab9071, 1:2000), rabbit anti-HA (Cell Signaling Technology, \#3724, 1:2000), mouse anti-Flag (ABclonal Cat\# AE005, RRID:AB_2770401, 1:2000) and mouse anti-GAPDH (Cwbiotech, 1:5000). Goat anti-mouse or anti-rabbit IgG secondary antibodies were coupled to Horseradish Peroxidase (HRP, Cwbiotech China), antibody complexes were detected using Pierce ECL Plus Western blotting substrate (Thermo Scientific). Chemiluminescence was detected using the ChemiDoc Imaging System (Tanon, China).

\section{Co-immunoprecipitation assays}

For co-immunoprecipitation analysis, 293T cells were transfected with vector plasmid or plasmids expressing 
HA-tagged MxB proteins. The cells were then harvested and washed with ice-cold PBS, resuspended in NP40 lysis buffer (beyotime) $48 \mathrm{~h}$ after transfection. Lysate was centrifuged at $12,000 \mathrm{~g}$ for $5 \mathrm{~min}$ at $4{ }^{\circ} \mathrm{C}$ and the supernatant was immunoprecipitated with control rabbit IgG (ABclonal) or anti-NUP358 antibody (Abcam) by incubating with Protein-G Sepharose (GE Healthcare) at $4{ }^{\circ} \mathrm{C}$ on rotospin for $4 \mathrm{~h}$. The immunoprecipitates were then washed with PBS twice, followed by a final wash with lysis buffer before eluting in $2 \times$ SDS-PAGE loading dye.

\section{Immunofluorescence Confocal Microscopy}

Cells cultured on 20-mm-diameter Glass Bottom Cell Culture Dish (Cell-Nest) were fixed with $4 \%$ paraformaldehyde for 20 min, washed with PBS three times, and permeabilized with $0.25 \%$ Triton-X 100 for $10 \mathrm{~min}$. The permeabilized cells were blocked with PBS containing 3\% BSA for $1 \mathrm{~h}$ at $37^{\circ} \mathrm{C}$ and stained with 1:200 dilution of anti-NUP358 antibody, anti-p24 antibody and blocking buffer for overnight at $4{ }^{\circ} \mathrm{C}$. Cells were washed three times with PBS, then were incubated with a 1:500 dilution of a Dylight 549-conjugated goat anti-mouse IgG antibody (Invitrogen), Dylight 488-conjugated goat antirabbit IgG antibody and blocking buffer for $1 \mathrm{~h}$ at $37^{\circ} \mathrm{C}$ and then washed with PBS three times. Cells were stained with Hoescht 33342 (Invitrogen) diluted to a concentration of $1 \mathrm{mg} / \mathrm{mL}$ for 3-5 min, following three washes with PBS. Subsequently, samples were mounted for fluorescent microscopy by using the Antifade Mounting Medium (beyotime). Images were obtained with Leica confocal microscope (Leica-LCS-SP8-STED, Germany) using a $63 \times$ objective and were analyzed with Leica Application Suite X software and Image Pro-Plus 6.0.

\section{Real-time PCR to detect HIV-1 reverse transcription products}

The total DNA was isolated from the cells $24 \mathrm{~h}$ or $48 \mathrm{~h}$ post infection using TRIZOL (Invitrogen) as the manufactures protocol and $100 \mathrm{ng}$ of each sample was used for realtime PCR analysis using $2 \times$ TaqMan Fast qPCR Master Mix (BBI Life Sciences). The second strand transfer products (Late RT) were detected using primers U5 forward, 5'-CAGACC CTTTTAGTCAGTGTGGAA- ${ }^{\prime}$ and U5 reverse, $5^{\prime}$-CTCTGGCTTTACTTTCGCTTTC A-3', with U5 probe, 5'-(FAM)-TCTCTAGCAGTG GCGCCCGAACA-(TAMRA)-3'. 2-LTR circle products were detected using primers 2-LTR forward, 5'-AAC TAGGGAAC CCACTGCTTAAG-3' and 2-LTR reverse, $5^{\prime}$-TCCACAGATCAAGGATATCTTGTC-3', with 2-LTR probe 5'-(FAM)-ACACTACTTGAAGCACTCAAGGCA AGCTTT(TAMRA)-3' [49]. Integrated (provirus) DNA was analysed using Alu PCR [50]. In brief, 16 cycles of pre-amplification $\left(15 \mathrm{~s}\right.$ at $94{ }^{\circ} \mathrm{C}, 15 \mathrm{~s}$ at $55^{\circ} \mathrm{C}, 100 \mathrm{~s}$ at
$72{ }^{\circ} \mathrm{C}$ ) were conducted with Taq DNA Polymerase (Invitrogen) using $600 \mathrm{nM}$ of $\mathrm{U} 5$ forward primer and $100 \mathrm{nM}$ of genomic Alu reverse primer, 5'-TGCTGGGATTAC AGGCGTGAG- $3^{\prime}$ in $1 \mu$ l, second-round qPCR was performed on preamplification products using the U5 forward and U5 reverse primers with the U5 probe. qPCR reactions were performed in triplicate, in universal PCR master mix using $900 \mathrm{nM}$ of each primer and $250 \mathrm{nM}$ probe. After $10 \mathrm{~min}$ at $95{ }^{\circ} \mathrm{C}$, reactions were cycled through $15 \mathrm{~s}$ at $95{ }^{\circ} \mathrm{C}$ followed by $1 \mathrm{~min}$ at $60{ }^{\circ} \mathrm{C}$ for 40 repeats. Quantitative RT-PCR was performed using BioRad CFX96 instrument (Bio-Rad, USA). GAPDH was also quantified in each sample to normalize HIV-1 cycle threshold $(\mathrm{Ct})$ values by GAPDH $\mathrm{Ct}$ values to generate $\Delta \Delta \mathrm{Ct}$ values.

\section{Statistical analysis}

Where appropriate, data are expressed as mean $\pm S D$ of triplicate cultures. Count data from immunofluorescence confocal assay with more than two groups were analysed by Kruskal-Wallis test. All other grouped data were analysed by one-way ANOVA. Statistical analysis was performed with GraphPad InStat statistical software (GraphPad Software, La Jolla, CA, USA). Statistical significance was defined as $\mathrm{p}<0.05$.

\section{Supplementary information}

Supplementary information accompanies this paper at https://doi. org/10.1186/s12977-020-00524-2.

Additional file 1. MxB inhibits nuclear import and integration of HIV-1 reverse transcripts. (a) Expression of MxB in HeLa cell lines. Location of MxB in HeLa-Ctrl and HeLa-MxB cells was shown in left. HeLa-Ctrl and HeLa- MxB cells were fixed and stained for MxB (red) and DAPI (blue) for cell nuclei. A representative image was depicted. Western blot of the expression of MxB in HeLa-Ctrl and HeLa-MxB cells was shown in right panel. (b) HeLa-Ctrl and HeLa-MxB cells were infected with VSV-G pseudotyped HIV-1 luciferase reporter virus, infectivity was determined $48 \mathrm{~h}$ post infection. (c) HeLa-Ctrl and HeLa-MxB cells were incubated with VSV-G pseudotyped HIV-1 luciferase reporter virus, QPCR analysis of HIV-1 Late RT DNA, 2-LTR circles and Integrated DNA was preformed $24 \mathrm{~h}$ post infection. Results were a summary of 3 independent experiments, an unpaired t test was performed (NS, not significant, ${ }^{*} p<0.05$, ${ }^{* *} p<0.01$ and ${ }^{* * *} p<0.001$ ). (d) Primary MDMs were isolated from three independent donors and transduced with lentivirus overexpressing MxB. $48 \mathrm{~h}$ later, cells were challenged with $\mathrm{HIV}-1_{\text {Bal }}$ and infectivity was determined $48 \mathrm{~h}$ later. (e) Primary $\mathrm{CD}^{+}{ }^{\mathrm{T}} \mathrm{T}$ cells were isolated from three independent donors and transduced with lentivirus overexpressing MxB. 48 h later, cells were challenged with HIV-1 ${ }_{\mathrm{NL} 4-3}$ and infectivity was determined $48 \mathrm{~h}$ later. The mean \pm SD of three technical replicates were shown for each donor.

Additional file 2. MxB inhibits HIV-1 ${ }_{W T}$ but not HIV-1 ${ }_{N 74 D}$ viral replication. HeLa-Ctrl and HeLa-MxB cells were synchronously infected with VSV-G pseudotyped HIV-1 luciferase reporter virus bearing either the wildtype (WT) CA or N74D CA mutant. Infectivity was determined $48 \mathrm{~h}$ post infection by luciferase assay (a) and p24 protein expression (b). Results were a summary of 3 independent experiments, an unpaired t test was performed (NS, not significant, ${ }^{*} p<0.05$, ${ }^{* *} p<0.01$ and ${ }^{* * *} p<0.001$ ).

Additional file 3. Overexpression of CPSF6 decreases HIV-1 nuclear import but not viral infection in the presence of MxB. (a) HeLa-Ctrl and 
HeLa-MxB cells were not transfected (Mock) or transfected with plasmid expressing CPSF6-Flag protein or empty vector. $48 \mathrm{~h}$ after transfection, the expression levels of CPSF6 were monitored by western blot. (b, c) Transfected cells were then incubated with VSV-G pseudotyped HIV-1 luciferase reporter virus, infectivity was determined $48 \mathrm{~h}$ post infection by luciferase assay (b) and p24 protein expression (c). (d) qPCR analysis of HIV-1 Late RT DNA, 2-LTR circles and Integrated DNA was preformed $24 \mathrm{~h}$ post infection. Results were a summary of 3 independent experiments, an unpaired t test was performed (NS, not significant, ${ }^{*} p<0.05,{ }^{* *} p<0.01$ and $\left.{ }^{* * *} p<0.001\right)$.

\section{Abbreviations}

Mx2/MxB: Myxovirus resistance 2; HIV-1: Human immunodeficiency virus 1; CPSF6: Cleavage and polyadenylation specificity factor subunit 6; PIC: Pre-integration complex; CA: Capsid protein; IN: Integrase; NC: Nucleocapsid; MA: Matrix; Vpr: Viral protein R; RT: Reverse transcriptase; HTNV: Hantaan virus; HBV: Hepatitis B virus; HCV: Hepatitis C virus; SIV: Simian immunodeficiency viruses; EIAV: Equine infectious anaemia virus; FIV: Feline immunodeficiency virus; LEDGF/p75: Lens epithelium-derived growth factor; BAF: Barrier-toautointegration factor; INI1: Integrase interactor 1; NPC: Nuclear pore complex; NUPs: Nucleoporins; CypA: Cyclophilin A; TNPO3: Transportin 3; NLS: Nuclear localization sequence; PF74: PF-3450074; MDMs: Monocyte-derived macrophages; PBMCs: Peripheral blood mononuclear cells; GM-CSF: Granulocyte macrophage colony-stimulating factor; FBS: Fetal bovine serum; rlL-2: Recombinant IL-2; PEl: Polyethylenimine; VSV-G: Vesicular stomatitis virus G protein; DMSO: Dimethyl sulfoxide.

\section{Acknowledgements}

We are grateful to Prof. Wenzhe Ho for his working on the manuscript, and to the Medical Research Center for Structural Biology, Wuhan University School of Basic Medical Sciences for providing experimental facilitates.

\section{Authors' contributions}

LX carried out all the experiments, collected data and wrote this manuscript. LC checked and revised the manuscript. CZ,TY, ZJ, and MW helped to finish the experiments. $L X, L C, H X, W H$, and YF designed the experiments and analyzed the data. YZ, JW and HH provided assistance and advice on the project. All authors reviewed the results and commented on the manuscript. All authors read and approved the final manuscript.

\section{Funding}

This work was supported by the National Natural Science Foundation of China (81271818 and 81471940 to YF, and 81471941,81871659 and 81828005 to $\mathrm{WH})$.

\section{Availability of data and materials}

All data generated or analysed during this study are included in this published article and its additional files.

\section{Ethics approval and consent to participate}

Acquisition of the blood samples used in this study was approved by the ethics committee of Wuhan University School of Medicine (WUSM, \#14010). All donors gave written informed consent.

\section{Consent for publication}

Not applicable.

\section{Competing interests}

The authors declare that they have no competing interests.

\section{Author details}

1 State Key Laboratory of Virology/Institute of Medical Virology/Hubei Province Key Laboratory of Allergy \& Immunology, School of Basic Medical Sciences, Wuhan University, Wuhan, Hubei, People's Republic of China. ${ }^{2}$ Department of Zoology, College of Life Sciences, Nanjing Agriculture University, Nanjing, Jiangsu, People's Republic of China. ${ }^{3}$ Key Laboratory of Molecular Virology and Immunology, Institute Pasteur of Shanghai, Chinese Academy of Sciences, Shanghai, People's Republic of China. ${ }^{4}$ Department of Microbiology and Immunology, Sealy Center for Vaccine Development and Institute for Human Infections and Immunity, University of Texas Medical Branch, Galveston, TX, USA.

Received: 17 March 2020 Accepted: 16 June 2020

Published online: 29 June 2020

\section{References}

1. King MC, Raposo G, Lemmon MA. Inhibition of nuclear import and cellcycle progression by mutated forms of the dynamin-like GTPase MxB. Proc Natl Acad Sci USA. 2004;101:8957-62.

2. Kane M, Yadav SS, Bitzegeio J, Kutluay SB, Zang T, Wilson SJ, Schoggins JW Rice CM, Yamashita M, Hatziioannou T, Bieniasz PD. MX2 is an interferoninduced inhibitor of HIV-1 infection. Nature. 2013;502:563-6.

3. Goujon C, Moncorge O, Bauby H, Doyle T, Ward CC, Schaller T, Hue S, Barclay WS, Schulz R, Malim MH. Human MX2 is an interferon-induced post-entry inhibitor of HIV-1 infection. Nature. 2013;502:559-62.

4. Liu Z, Pan Q, Ding S, Qian J, Xu F, Zhou J, Cen S, Guo F, Liang C. The interferon-inducible MxB protein inhibits HIV-1 infection. Cell Host Microbe. 2013;14:398-410.

5. Crameri M, Bauer M, Caduff N, Walker R, Steiner F, Franzoso FD, Gujer C, Boucke K, Kucera T, Zbinden A, et al. MxB is an interferon-induced restriction factor of human herpesviruses. Nat Commun. 1980;2018:9.

6. Schilling M, Bulli L, Weigang S, Graf L, Naumann S, Patzina C, Wagner V, Bauersfeld L, Goujon C, Hengel H, et al. Human MxB protein is a panherpesvirus restriction factor. J Virol. 2018;92:e01056.

7. Li N, Luo F, Chen Q, Zhu N, Wang H, Xie L, Xiong H, Yue M, Zhang Y, Feng Y, Hou W. IFN-lambdas inhibit Hantaan virus infection through the JAK-STAT pathway and expression of Mx2 protein. Genes Immun. 2019;20:234-44.

8. Yi D-R, An N, Liu Z-L, Xu F-W, Raniga K, Li Q-J, Zhou R, Wang J, Zhang Y-X, Zhou J-M, et al. Human MxB inhibits the replication of hepatitis C virus. J Virol. 2018;93:e01285

9. Wang YX, Niklasch M, Liu T, Wang Y, Shi B, Yuan W, Baumert TF, Yuan Z, Tong S, Nassal M, Wen YM. Interferon-inducible MX2 is a host restriction factor of hepatitis B virus replication. J Hepatol. 2019. https://doi. org/10.1016/j.jhep.2019.12.009.

10. Fribourgh JL, Nguyen HC, Matreyek KA, Alvarez FJD, Summers BJ, Dewdney TG, Aiken C, Zhang P, Engelman A, Xiong Y. Structural insight into HIV-1 restriction by MxB. Cell Host Microbe. 2014;16:627-38.

11. Kong J, Xu B, Wei W, Wang X, Xie W, Yu XF. Characterization of the aminoterminal domain of $\mathrm{M} \times 2 / \mathrm{M} \times \mathrm{B}$-dependent interaction with the HIV-1 capsid. Protein Cell. 2014;5:954-7.

12. Buffone C, Schulte B, Opp S, Diaz-Griffero F. Contribution of MxB oligomerization to HIV-1 capsid binding and restriction. J Virol. 2015:89:3285-94.

13. Busnadiego I, Kane M, Rihn SJ, Preugschas HF, Hughes J, Blanco-Melo D, Strouvelle VP, Zang TM, Willett BJ, Boutell C, et al. Host and viral determinants of Mx2 antiretroviral activity. J Virol. 2014;88:7738-52.

14. Fricke T, White TE, Schulte B, de Souza Aranha Vieira DA, Dharan A, Campbell EM, Brandariz-Nunez F. MxB binds to the HIV-1 core and prevents the uncoating process of HIV-1. Retrovirology. 2014;11:68.

15. Ding J, Zhao J, Yang Z, Ma L, Mi Z, Wu Y, Guo J, Zhou J, Li X, Guo Y, et al. Microbial natural product alternariol 5-O-methyl ether inhibits HIV-1 integration by blocking nuclear import of the pre-integration complex. Viruses. 2017;9:105.

16. Raghavendra NK, Shkriabai N, Graham R, Hess S, Kvaratskhelia M, Wu L. Identification of host proteins associated with HIV-1 preintegration complexes isolated from infected CD4+ cells. Retrovirology. 2010;7:66.

17. Matreyek KA, Wang W, Serrao E, Singh PK, Levin HL, Engelman A. Host and viral determinants for MxB restriction of HIV-1 infection. Retrovirology. 2014;11:90.

18. Haller O, Staeheli P, Schwemmle M, Kochs G. Mx GTPases: dynamin-like antiviral machines of innate immunity. Trends Microbiol. 2015;23:154-63.

19. Woodward CL, Chow SA. The nuclear pore complex: a new dynamic in HIV-1 replication. Nucleus. 2010;1:18-22.

20. Matreyek KA, Engelman A. Viral and cellular requirements for the nuclear entry of retroviral preintegration nucleoprotein complexes. Viruses. 2013;5:2483-511.

21. Bin Hamid F, Kim J, Shin CG. Cellular and viral determinants of retroviral nuclear entry. Can J Microbiol. 2016;62:1-15. 
22. Strambio-De-Castillia C, Niepel M, Rout MP. The nuclear pore complex bridging nuclear transport and gene regulation. Nat Rev Mol Cell Biol. 2010;11:490-501.

23. Schaller T, Ocwieja KE, Rasaiyaah J, Price AJ, Brady TL, Roth SL, Hue S, Fletcher AJ, Lee K, KewalRamani VN, et al. HIV-1 capsid-cyclophilin interactions determine nuclear import pathway, integration targeting and replication efficiency. PLoS Pathog. 2011;7:e1002439.

24. Bichel K, Price AJ, Schaller T, Towers GJ, Freund SMV, James LC. HIV-1 capsid undergoes coupled binding and isomerization by the nuclear pore protein NUP358. Retrovirology. 2013;10:81.

25. Di Nunzio F, Danckaert A, Fricke T, Perez P, Fernandez J, Perret E, Roux P, Shorte S, Charneau P, Diaz-Griffero F, Arhel NJ. Human nucleoporins promote HIV-1 docking at the nuclear pore, nuclear import and integration. PLOS ONE. 2012;7:e46037.

26. Zhang R, Mehla R, Chauhan A. Perturbation of host nuclear membrane component RanBP2 impairs the nuclear import of human immunodeficiency virus -1 preintegration complex (DNA). PLoS ONE. 2010;5:e15620

27. Lee K, Ambrose Z, Martin TD, Oztop I, Mulky A, Julias JG, Vandegraaff N, Baumann JG, Wang R, Yuen W, et al. Flexible use of nuclear import pathways by HIV-1. Cell Host Microbe. 2010;7:221-33.

28. Dharan A, Talley S, Tripathi A, Mamede JI, Majetschak M, Hope TJ, Campbell EM. KIF5B and Nup358 Cooperatively Mediate the Nuclear Import of HIV-1 during Infection. PLoS Pathog. 2016;12:e1005700.

29. Chin CR, Perreira JM, Savidis G, Portmann JM, Aker AM, Feeley EM, Smith MC, Brass AL. Direct visualization of HIV-1 replication intermediates shows that capsid and CPSF6 modulate HIV-1 intra-nuclear invasion and integration. Cell Rep. 2015;13:1717-31.

30. Peng K, Muranyi W, Glass B, Laketa V, Yant SR, Tsai L, Cihlar T, Muller B, Krausslich HG. Quantitative microscopy of functional HIV post-entry complexes reveals association of replication with the viral capsid. Elife. 2014:3:e04114.

31. Ning J, Zhong Z, Fischer DK, Harris G, Watkins SC, Ambrose Z, Zhang P. Truncated CPSF6 forms higher-order complexes that bind and disrupt HIV-1 capsid. J Virol. 2018;92:e00368.

32. De laco A, Santoni F, Vannier A, Guipponi M, Antonarakis S, Luban J. TNPO3 protects HIV-1 replication from CPSF6-mediated capsid stabilization in the host cell cytoplasm. Retrovirology. 2013;10:20.

33. Price AJ, Fletcher AJ, Schaller T, Elliott T, Lee K, KewalRamani VN, Chin JW, Towers GJ, James LC. CPSF6 defines a conserved capsid interface that modulates HIV-1 replication. PLoS Pathog. 2012;8:e1002896.

34. Di Nunzio F, Fricke T, Miccio A, Valle-Casuso JC, Perez P, Souque P, Rizzi E, Severgnini M, Mavilio F, Charneau P, Diaz-Griffero F. Nup153 and Nup98 bind the HIV-1 core and contribute to the early steps of HIV-1 replication. Virology. 2013;440:8-18.

35. Matreyek KA, Yucel SS, Li X, Engelman A. Nucleoporin NUP153 phenylalanine-glycine motifs engage a common binding pocket within the HIV-1 capsid protein to mediate lentiviral infectivity. PLoS Pathog. 2013;9:e1003693.

36. Zhou J, Price AJ, Halambage UD, James LC, Aiken C. HIV-1 resistance to the capsid-targeting inhibitor PF74 results in altered dependence on host factors required for virus nuclear entry. J Virol. 2015;89:9068-79.
37. Marx A, Alian A. The road less traveled: HIV's use of alternative routes through cellular pathways. J Virol. 2015;89:5204-12.

38. Goujon C, Greenbury RA, Papaioannou S, Doyle T, Malim MH. A triplearginine motif in the amino-terminal domain and oligomerization are required for HIV-1 inhibition by human MX2. J Virol. 2015;89:4676-80.

39. Dicks MDJ, Betancor G, Jimenez-Guardeno JM, Pessel-Vivares L, Apolonia L, Goujon C, Malim MH. Multiple components of the nuclear pore complex interact with the amino-terminus of MX2 to facilitate HIV-1 restriction. PLoS Pathog. 2018;14:e1007408.

40. Liu Z, Pan Q, Liang Z, Qiao W, Cen S, Liang C. The highly polymorphic cyclophilin A-binding loop in HIV-1 capsid modulates viral resistance to MxB. Retrovirology. 2015;12:1.

41. Chen NY, Zhou L, Gane PJ, Opp S, Ball NJ, Nicastro G, Zufferey M, Buffone C, Luban J, Selwood D, et al. HIV-1 capsid is involved in post-nuclear entry steps. Retrovirology. 2016;13:28.

42. Campbell EM, Hope TJ. HIV-1 capsid: the multifaceted key player in HIV-1 infection. Nat Rev Microbiol. 2015;13:471-83.

43. Engelman AN, Singh PK. Cellular and molecular mechanisms of HIV-1 integration targeting. Cell Mol Life Sci. 2018;75:2491-507.

44. Francis AC, Melikyan GB. Single HIV-1 imaging reveals progression of infection through CA-dependent steps of docking at the nuclear pore, uncoating, and nuclear transport. Cell Host Microbe. 2018;23(536-548):e536.

45. Bhattacharya A, Alam SL, Fricke T, Zadrozny K, Sedzicki J, Taylor AB, Demeler B, Pornillos O, Ganser-Pornillos BK, Diaz-Griffero F, et al. Structural basis of HIV-1 capsid recognition by PF74 and CPSF6. Proc Natl Acad Sci USA. 2014;111:18625-30.

46. Kane M, Rebensburg SV, Takata MA, Zang TM, Yamashita M, Kvaratskhelia M, Bieniasz PD. Nuclear pore heterogeneity influences HIV-1 infection and the antiviral activity of MX2. Elife. 2018;7:e35738.

47. Wei W, Guo H, Ma M, Markham R, Yu XF. Accumulation of MxB/Mx2resistant HIV-1 capsid variants during expansion of the HIV-1 epidemic in human populations. EBioMedicine. 2016:8:230-6.

48. Nakayama EE, Saito A, Sultana T, Jin Z, Nohata K, Shibata M, Hosoi M, Motomura K, Shioda T, Sangkitporn S, et al. Naturally occurring mutations in HIV-1 CRF01_AE capsid affect viral sensitivity to restriction factors. AIDS Res Hum Retroviruses. 2018;34:382-92.

49. Kitagawa Y, Kameoka M, Shoji-Kawata S, Iwabu Y, Mizuta H, Tokunaga K, Fujino M, Natori Y, Yura Y, Ikuta K. Inhibitory function of adapter-related protein complex 2 alpha 1 subunit in the process of nuclear translocation of human immunodeficiency virus type 1 genome. Virology. 2008:373:171-80

50. Butler SL, Hansen MS, Bushman FD. A quantitative assay for HIV DNA integration in vivo. Nat Med. 2001;7:631-4.

\section{Publisher's Note}

Springer Nature remains neutral with regard to jurisdictional claims in published maps and institutional affiliations.

Ready to submit your research? Choose BMC and benefit from

- fast, convenient online submission

- thorough peer review by experienced researchers in your field

- rapid publication on acceptance

- support for research data, including large and complex data types

- gold Open Access which fosters wider collaboration and increased citations

- maximum visibility for your research: over $100 \mathrm{M}$ website views per year

At BMC, research is always in progress.

Learn more biomedcentral.com/submissions 